\title{
Frequiência de Ocorrência dos Fones e Listas de Frases Foneticamente Balanceadas no Português Falado no Rio de Janeiro
}

\author{
Abraham Alcaim, José Alberto Solewicz e João Antônio de Moraes ${ }^{1}$ \\ Este trabalho tem por objetivo principal a construção de um conjunto de vinte listas de dez frases fonetica- \\ mete balanceadas para o português falado no Rio de Janeiro. Para o estabelecimento das listas de frases \\ procedeu-se a um levantamento prévio da freqüència relativa dos fones no português falado no Rio de Ja- \\ neiro. apresentado na primeira parte do trabalho. Foi utilizado como indicador do balanceamento das fra- \\ ses o valor da distância qui-quadrado $\left(\chi^{2}\right)$ observada entre a frequiência dos fones em cada uma das listas e \\ sua ocorrência na língua falada. Uma da aplicações principais das listas de frases balanceadas reside na \\ avaliação subjetiva da qualidade de voz processada por codificadores digitais.
}

\section{Introduç̃̃o}

Em diversas aplicações na área de processamento de sinais de voz, como, por exemplo, codificação digital, síntese, etc., é de fundamental importância a utilização de testes de avaliação subjetiva da qualidade do sinal processado [1]-[3]. Um destes testes, denominado teste da nota de opinião média, baseia-se na atribuição, por parte de um grupo de ouvintes, de notas que variam de 1 , significando qualidade inaceitável, a 5, significando qualidade excelente do sinal de voz processado.

Na realização desses testes formais de qualidade de voz é de interesse, evidentemente, que o material de voz utilizado reflita de forma significativa a ocorrência dos sons da fala. Como a preparação e a aplicação dos testes envolvem um tempo de trabalho razoavelmente grande, é desejável que o material de voz utilizado não seja longo. Neste trabalho são propostas vinte listas de dez frases, sendo cada uma das listas foneticamente balanceada no sentido de que a frequiência de ocorrência dos fones se aproxima de modo siginificativo daquela com que ocorrem na língua falada. A significância é aqui determinada com base na distância qui-quadrado $\left(\chi^{2}\right)$ encontrada entre a distribuição dos fones no material de voz utilizado e aquela observada na língua portuguesa. Para construir as listas de frases balanceadas faz-se necessário, portanto, determinar primeiramente a estatística de ocorrência dos sons da língua.

1 A. Alcaim é professor e J.A. Solewicz é aluno de pós-graduação do Centro de Estudos e Telecomunicações da PUC/Rio, Rio de Janeiro-RJ. J.A. Moraes é professor da Pós-graduação da Faculdade de Letras (Laboratório de Fonética Acústica) da Universidade Federal do Rio de Janeiro, Rio de Janeiro-RJ

Revista da Sociedade Brasileira de Telecomunicações 
Na seção 2 deste trabalho é feito um levantamento estatístico dos fones do português falado no Rio de Janeiro. Os resultados desse levantamento são então empregados na seção 3 , seção em que é descrito o procedimento para construção de cada lista de frases, usando-se o critério $\chi^{2}<15$ para classificar a lista como foneticamente balanceada. Em seguida, são apresentadas as vinte listas de dez frases juntamente com o número total de fones e o valor de $\chi^{2}$ obtido em cada lista (listas de de $z$ frases balanceadas na língua inglesa e na língua francesa podem ser encontradas, respectivamente, em [1] e [2]).

\section{Frequiência Relativa dos Fones}

\subsection{Considerações Preliminares}

No estabelecimento da distribuição estatística dos sons de uma língua. a primeira questão que se coloca é a do nível de abstração em que devemos nos situar. Deve-se optar pelo cômputo dos fonemas propriamente ditos - unidades mais abstratas cuja alternância num mesmo contex to fônico distingue o significado de vocábulos -, ou considerar os fones, que correspondem à realização dos fonemas na fala, independentemente de seu caráter distintivo?

Fonemas seriam, por exemplo, em português $/ \mathrm{t} / \mathrm{d} / \mathrm{d} / \mathrm{n} /$, (cf. tela, dela, nela), enquanto que corresponderiam a fones as diferentes formas que, em distintas regiões dopaís, o fonema / $/$ / assume diante da vogal /i/, como na palavra "tia", por exemplo: [tia] no Nordeste, com uma articulação puramente oclusiva,[t $\mathrm{i}$ ia] no Rio de Janeiro, com uma articulação africada, onde à oclusão se segue um ruído fricativo similar ao do início da palavra "chuva", [tsia] em certas regiões de São Paulo, onde o ruído fricativo se assemelha a um $[\mathrm{s}]$.

Observe-se que a classificação de um som como fone ou fonema pressupõe uma análise do sistema fonológico específico de cada língua. Assim, os três fones do fonema /t/ aqui citados em relação ao português constituem, em italiano, não mais fones, mas fonemas distintos, pois sua alternância corresponde a uma oposição de significados.

De um ponto de vista mais estritamente lingüístico, a primeira opção - o cômputodos fonemas -, por ser mais geral, oferece um interesse mais amplo, proporcionando um quadro da frequiência relativa dos sons da língua, independentemente de suas variações regionais, sociais, estilísticas. Esse quadro nos informa, por exemplo, da maior ou menor integração de um dado fonema ao sistema, o que pode explicar fatos relativos a mudanças fonéticas já ocorridas ou em curso. É esse quadro da frequiência dos fonemas que habitualmente se tenta estabelecer, a partir muitas vezes de textos escritos (cf. as estatísticas de distribuição de consoantes de 17 línguas fornecidas em [4] $)^{1}$.

1 Oestabelecimento da frequêencia de ocorrência das vogais e consoantes do português europeu, a partir da leitura de um pequeno corpus ( 40 frases comportando cerca de 20 fonemas cada uma) foi feita por Delgado-Martins [5]. 
Para questões ligadas à avaliação da qualidade de sinais de voz processados por um sistema de codificação digital, ou transmitidos através de sistemas de comunicações, por exemplo, é de interesse, ao contrário, estabelecer a frequiência relativa dos fones, frequiência essa baseada na pronúncia efetiva de um determinado dialeto, uma vez que serão, em última instância, fones, e não fonemas, que deverão se reproduzidos pelo sistema em questão.

\subsection{Métodos e Resultados}

Contrariamente ao que ocorre no levantamento de fonemas, quando, a rigor, a análise do texto escrito basta, a audição de textos de fala espontânea aqui se impõe, uma vez que a realização efetiva dos fones não é, na maior parte das vezes, predizível a partir da transcrição ortográfica.

O corpus para a presente análise constituiu-se de inquéritos, gravados em fitas magnéticas, do projeto NURC-RJ - Projeto de Estudo da Norma Lingüística Urbana Culta na cidade do Rio de Janeiro (cf. Callou e Marques [6]).

A escolha da variante do Rio de Janeiro como base para o presente estudo, além de obedecer a razões de ordem prática (facilidade na obtenção dos dados a serem transcritos, disponibilidade de ouvintes para testes auditivos posteriores), justifica-se por ser ela identificada como uma variante de prestígio do português do Brasil ${ }^{1}$.

Foram selecionados 10 inquéritos do tipo "entrevista entre informante e documentador", tendo sido, numa primeira etapa, transcritos foneticamente, em cada inquérito, trechos previamente demarcados de aproximadamente 1.000 fones, perfazendo um total de 10.147 fones. Os dez falantes eram todos cariocas. de nível superior, tendo sido selecionados os inquéritos de maneira a cobrir assuntos diferenciados, falantes de ambos os sexos e pertencentes a três faixas etárias: I) 25-35 anos, II) 36-55 anos, III) 56 anos em diante.

A audição e a transcrição fonética das entrevistas foram realizadas por um foneticista experimentado, tendo sido adotado como sistema de notação o Alfabeto Fonético Internacional. Os trechos a serem transcritos eram ouvidos tantas vezes quanto necessário para que se chegasse a uma transcrição considerada fidedigna do que fora emitido. Eventuais repetições de palavras ou sintagmas, típicas de fenômenos de hesitação, (p. ex. "ele sentou na cadeira... na cadeira da ponta") não foram consideradas no cômputo dos fones.

Uma frase como "Hoje em dia, os hotéis baratos são poucos" poderia ser emitida (e transcrita) da seguinte forma:

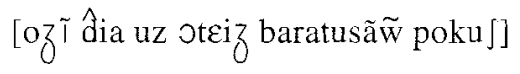

1 Lembramos que a pronúncia carioca foi considerada, em dois congressos (CLNC [7] e CLFT [8]), a pronúncia padrão brasileira.

Revista da Sociedade Brasileira de Telecomunicações 
Note-se aqui a realização do fonema /s/ com [z], entre vogais (oS hoteis), como [z], diante de consoante sonora (hoteiS baratos), como / / em posição final (poucoS). Observe-se ainda a realização africada de /d/ diante de /i/ (em "Dia", aqui representado por $\hat{\mathrm{d}}$ ) e a queda de segmentos na juntura de vocábulos (hojE em dia) ou em posição interna a eles (poUcos).

\begin{tabular}{|c|c|c|}
\hline Fone & Símbolo no computador & Excmplo \\
\hline $\mathrm{a}$ & $\mathrm{A}$ & ala \\
\hline$\varepsilon$ & {[} & ela \\
\hline $\mathrm{e}$ & $\mathrm{E}$ & ele \\
\hline $\mathrm{i}$ & I & vida \\
\hline 0 & 1 & loja \\
\hline o & $\mathrm{O}$ & globo \\
\hline$u$ & $\mathrm{U}^{\mathrm{T}}$ & lucro \\
\hline$\tilde{a}$ & $<$ & $\operatorname{maçãa}$ \\
\hline$\tilde{\mathrm{e}}$ & $=$ & centro \\
\hline$\tilde{1}$ & $>$ & $\operatorname{sim}$ \\
\hline$\tilde{0}$ & $?$ & som \\
\hline$\tilde{\mathrm{u}}$ & $@$ & $\mathbf{u m}$ \\
\hline $\mathrm{j}$ & $\mathbf{J}$ & dois \\
\hline w & W & mau \\
\hline$\tilde{j}$ & ] & tem \\
\hline$\tilde{\mathrm{W}}$ & $\wedge$ & กão \\
\hline $\mathrm{p}$ & $\mathbf{P}$ & pato \\
\hline 1 & $\mathrm{~T}$ & tato \\
\hline $\mathrm{k}$ & $\mathrm{K}$ & cato \\
\hline$b$ & $\mathrm{~B}$ & bato \\
\hline d & $\mathrm{D}$ & dado \\
\hline $\mathrm{g}$ & $\mathrm{G}$ & gado \\
\hline $\mathrm{f}$ & $\mathrm{F}$ & fala \\
\hline $\mathrm{v}$ & $\mathrm{V}$ & vala \\
\hline s & $S$ & sala \\
\hline$z$ & $\mathrm{Z}$ & casa \\
\hline$r$ & $R$ & caro \\
\hline $\mathrm{m}$ & $\mathrm{M}$ & morte \\
\hline $\mathrm{n}$ & $\mathrm{N}$ & norte \\
\hline n & $Q$ & ninho \\
\hline 1 & $\mathrm{~L}$ & lado \\
\hline$\lambda$ & $\mathrm{C}$ & alho \\
\hline $\int$ & $\mathrm{H}$ & chave \\
\hline 3 & $Y$ & jogo \\
\hline $\mathrm{R}$ & $X$ & carro \\
\hline$\hat{\mathrm{d}}$ & : & dia \\
\hline$\hat{\mathrm{t}}$ & ; & tia \\
\hline
\end{tabular}

Tabela 1 - Quadro dos Fones 


\begin{tabular}{|c|c|c|c|c|c|c|c|c|c|c|c|}
\hline \multirow{2}{*}{ Fone } & \multicolumn{10}{|c|}{ Locutor } & \multirow{2}{*}{ Total } \\
\hline & 1 & 2 & 3 & 4 & 5 & 6 & 7 & 8 & 9 & 10 & \\
\hline$a$ & 144 & 128 & 152 & 125 & 112 & 137 & 131 & $\overline{123}$ & 144 & 117 & 1313 \\
\hline$\varepsilon$ & 18 & 23 & 37 & 7 & 28 & 28 & 13 & 17 & 13 & 10 & 194 \\
\hline $\mathrm{e}$ & 63 & 49 & 32 & 49 & 57 & 28 & 52 & 58 & 55 & 46 & 489 \\
\hline i & 54 & 93 & 91 & 64 & 97 & 90 & 98 & 107 & 63 & 113 & 870 \\
\hline 0 & 12 & 10 & 6 & 12 & 16 & 12 & 9 & 8 & 7 & 9 & 101 \\
\hline 0 & 18 & 26 & 16 & 29 & 28 & 28 & 35 & 24 & 34 & 37 & 275 \\
\hline $\mathrm{u}$ & 67 & 57 & 48 & 62 & 58 & 65 & 57 & 50 & 46 & 47 & 557 \\
\hline$\tilde{a}$ & 22 & 21 & 13 & 26 & 16 & 18 & 29 & 26 & 18 & 26 & 215 \\
\hline$\tilde{\mathrm{e}}$ & 29 & 11 & 28 & 19 & 24 & 33 & 14 & 13 & 37 & 25 & 233 \\
\hline$\tilde{i}$ & 23 & 17 & 21 & 24 & 22 & 18 & 12 & 14 & 15 & 12 & 178 \\
\hline$\tilde{\mathrm{o}}$ & 6 & 8 & 17 & 13 & 7 & 2 & 5 & 5 & 2 & 11 & 76 \\
\hline$\tilde{\mathrm{u}}$ & 8 & 14 & 12 & 15 & 9 & 13 & 6 & 9 & 24 & 19 & 129 \\
\hline j & 42 & 32 & 41 & 31 & 28 & 35 & 26 & 29 & 30 & 24 & 318 \\
\hline w & 47 & 35 & 29 & 41 & 36 & 17 & 35 & 31 & 28 & 25 & 324 \\
\hline$\tilde{j}$ & 12 & 12 & 23 & 20 & 11 & 22 & 9 & 8 & 20 & 13 & 150 \\
\hline$\tilde{\mathrm{W}}$ & 9 & 15 & 12 & 18 & 10 & 10 & 19 & 11 & 7 & 14 & 125 \\
\hline $\mathrm{p}$ & 33 & 14 & 19 & 16 & 16 & 28 & 20 & 24 & 33 & 29 & 232 \\
\hline $\mathrm{t}$ & 46 & 35 & 44 & 41 & 41 & 48 & 32 & 41 & 38 & 34 & 400 \\
\hline $\mathrm{k}$ & 49 & 36 & 44 & 51 & 34 & 50 & 27 & 44 & 35 & 55 & 425 \\
\hline b & 12 & 11 & 25 & 9 & 9 & 6 & 5 & 5 & 15 & 14 & 111 \\
\hline $\mathrm{d}$ & 39 & 33 & 24 & 28 & 17 & 22 & 36 & 29 & 20 & 20 & 268 \\
\hline $\mathrm{g}$ & 12 & 12 & 2 & 15 & 11 & 10 & 7 & 4 & 14 & 7 & 94 \\
\hline f & 9 & 27 & 13 & 8 & 14 & 12 & 10 & 15 & 19 & 21 & 148 \\
\hline $\mathrm{v}$ & 7 & 17 & 9 & 11 & 17 & 10 & 20 & 17 & 8 & 9 & 125 \\
\hline $\mathrm{s}$ & 30 & 34 & 41 & 38 & 48 & 47 & 37 & 35 & 56 & 58 & 424 \\
\hline z & 20 & 17 & 24 & 15 & 21 & 20 & 26 & 9 & 19 & 13 & 184 \\
\hline$r$ & 47 & 42 & 23 & 22 & 39 & 33 & 35 & 47 & 33 & 42 & 363 \\
\hline $\mathrm{m}$ & 46 & 25 & 42 & 53 & 41 & 41 & 32 & 47 & 40 & 51 & 418 \\
\hline $\mathrm{n}$ & 18 & 26 & 17 & 17 & 28 & 21 & 36 & 22 & 23 & 36 & 244 \\
\hline$n$ & 16 & 1 & 4 & 6 & 7 & 6 & 4 & 8 & 13 & 4 & 69 \\
\hline 1 & 33 & 23 & 14 & 18 & 12 & 10 & 17 & 16 & 20 & 12 & 175 \\
\hline$\lambda$ & 0 & 0 & 0 & 2 & 4 & 1 & 5 & 3 & 4 & 2 & 21 \\
\hline $\int$ & 22 & 27 & 19 & 23 & 13 & 31. & 8 & 36 & 31 & 5 & 215 \\
\hline 3 & 16 & 23 & 6 & 8 & 13 & 15 & 24 & 9 & 14 & 6 & 134 \\
\hline $\mathrm{R}$ & 28 & 13 & 14 & 26 & 19 & 24 & 38 & 15 & 13 & 19 & 209 \\
\hline$\hat{\mathrm{d}}$ & 20 & 23 & 36 & 15 & 17 & 15 & 19 & 25 & 9 & 16 & 195 \\
\hline$\hat{\mathfrak{t}}$ & 8 & 13 & 12 & 20 & 22 & 12 & 13 & 16 & 10 & 20 & 146 \\
\hline Tota] & 1085 & 1003 & 1010 & 997 & 1002 & 1018 & 1001 & 1000 & 1010 & 1021 & 10147 \\
\hline
\end{tabular}

Tabela 2 - Número de Fones por Locutor

Revista da Sociedade Brasileira de Telecomunicaçōes

volume 7 - Número 1 - Dezembro 1992 
O quadro dos fones e respectivos exemplos, acompanhado dos símbolos usados no computador, é fornecido na Tab.1. O número de vezes que cada fone ocorreu para cada locutor, o número total de fones por locutor e o total geral do número de fones são apresentados na Tab.2.

A frequiência relativa do i-ésimo fone, medida até o n-ésimo locutor, $\mathrm{F}_{\mathrm{i}}(\mathrm{n})$, é definida como a razão entre o número de aparições do fone até o n-ésimo locutor e onúmero total de fones que ocorreram até aquele locutor. Quando se aumenta progressivamente o número de locutores, as diferenças absolutas da frequiência relativa, $\left|F_{i}(n)-F_{i}(n-1)\right|$, tendem a diminuir. Essa tendência pode ser evidenciada através da soma dessas diferenças, observadas em relação aos 37 fones, em função do número de locutores:

$$
\varepsilon(\mathrm{n})=\sum_{\mathrm{i}=1}^{37}\left|\mathrm{~F}_{\mathrm{i}}(\mathrm{n})-\mathrm{F}_{\mathrm{i}}(\mathrm{n}-1)\right|
$$

O comportamento de $\varepsilon(n)$ é mostrado na Tab.3. Verifica-se nessa tabela que $\varepsilon(n)$ começa com um valor de $14,07 \%$ e atinge valores abaixo de $3,00 \%$ já a partir do oitavo locutor. Deve-se notar que esses valores são bastante baixns, considerando-se que eles correspondem à soma das diferenças encontradas para a totalidade dos 37 fones.

\begin{tabular}{c|c|c|c|c|c|c|c|c|c}
\hline $\mathrm{n}$ & 2 & 3 & 4 & 5 & 6 & 7 & 8 & 9 & 10 \\
\hline$\varepsilon(\mathrm{n})$ & 14,07 & 10,25 & 5,71 & 4,27 & 3,26 & 3,59 & 2,53 & 2,79 & 2,74 \\
\hline
\end{tabular}

Tabela 3 - Soma $\varepsilon(n)$ das Diferenças Absolutas das Freqüîncias Relativas em Função do Número n de Locutores (em porcentagem)

A frequiência relativa de ocorrência de cada fone, estabelecida com base nos 10 locutores, é fornecida na Tab.4. 


\begin{tabular}{|c|c|}
\hline$\overline{\text { Fone }}$ & Freqüèencia Relativa (\%) \\
\hline $\mathrm{a}$ & 12,94 \\
\hline$\varepsilon$ & 1,91 \\
\hline $\mathrm{e}$ & 4,82 \\
\hline i & 8.57 \\
\hline 0 & 1,00 \\
\hline o & 2,71 \\
\hline $\mathrm{u}$ & 5,49 \\
\hline$\tilde{a}$ & 2,12 \\
\hline$\tilde{\mathrm{e}}$ & 2,30 \\
\hline$\tilde{i}$ & 1.75 \\
\hline$\tilde{o}$ & 0,75 \\
\hline$\tilde{\mathrm{u}}$ & 1,27 \\
\hline $\mathrm{j}$ & 3,13 \\
\hline w & 3,19 \\
\hline$\tilde{\mathrm{j}}$ & 1,48 \\
\hline$\widetilde{\mathrm{W}}$ & 1,23 \\
\hline $\mathrm{p}$ & 2,29 \\
\hline$t$ & 3,94 \\
\hline $\mathrm{k}$ & 4,19 \\
\hline $\mathrm{b}$ & 1,09 \\
\hline $\mathrm{d}$ & 2,64 \\
\hline$g$ & 0,93 \\
\hline $\mathrm{f}$ & 1,46 \\
\hline v & 1,23 \\
\hline s & 4,18 \\
\hline z & 1,81 \\
\hline $\mathrm{r}$ & 3,58 \\
\hline $\mathrm{m}$ & 4,12 \\
\hline$n$ & 2,40 \\
\hline ก & 0,68 \\
\hline 1 & 1,72 \\
\hline$\lambda$ & 0,21 \\
\hline J & 2,12 \\
\hline 3 & 1,32 \\
\hline$R$ & 2,06 \\
\hline$\hat{d}$ & 1,92 \\
\hline$\hat{z}$ & 1,44 \\
\hline
\end{tabular}

Tabela 4 - Freqüência Relativa dos Fones

Revista da Sociedade Brasileira de Telecomunicaçōes 


\section{Listas de Frases Fonelicamente Balanceadas}

\subsection{Procedimento para Construção das Listas de Frases}

$\operatorname{Sejam}\left\{F_{i}, i=1, \ldots, 37\right\}$ as freqüências relativas esperadas dos 37 fones do português falado (valores da Tab.4 divididos por 100) e sejam $\left\{\mathrm{f}_{\mathrm{i}}=\mathrm{n}_{\mathrm{i}} / \mathrm{N} ; \mathrm{i}=1, \ldots, 37\right\}$ as frequiencias relativas observadas em uma lista de dez frases, onde $\mathrm{N}$ é o número de fones da lista e $n_{\mathrm{i}}$ é o número de vezes que o i-ésimo fone ocorreu na lista. Para que a lista de frases seja considerada foneticamente balanceada, é necessário que $\left\{\mathrm{f}_{\mathrm{i}}\right\}$ se aproxime suficientemente bem de $\left\{F_{i}\right.$ '.

Uma possibilidade de se determinar se $\left\{f_{i}\right\}$ se desvia ou não de forma significativa de $\left\{F_{i}\right\}$ é através do teste $\chi^{2}$ [9]. Nesse teste utiliza-se a distribuição $\chi^{2}$ com 36 graus de liberdade, onde

$$
\chi^{2}=\sum_{i=1}^{37} \frac{\left(n_{i}-N F_{i}\right)^{2}}{N F_{i}}
$$

Com base em valores tabelados [10], pode-se encontrar um número c tal que a probabilidade $P$ de $\chi^{2}$ ser maior que c é igual a um determinado valor $\alpha$. O teste $\chi^{2}$ consiste, então, em aceitar desvios que sejam inferiores a c. Um valor usualmente empregado para $\alpha$ é 0,05 . Nesse caso o valor de c para 36 graus de liberdade é de aproximadamente 51, consistindo o teste $\chi^{2}$ em aceitar valores que não excedam esse número. Apesar disso, decidiu-se empregar aqui um procedimento semelhante ao adotado em [2]. Serão aceitos apenas valores de $\chi^{2}<15$, uma vez que quanto menor for o valor de $\chi^{2}$, mais as freqüências relativas observadas nas frases $\left\{f_{i}\right\}$ se aproximarão das esperadas $\left\{F_{i}\right\}$. O valor limite de 15 para 36 graus de liberdade é, sem dúvida, bastante baixo. Com efeito, as tabelas de $\chi^{2}$ mostram que a probabilidade $\mathrm{P}\left(\chi^{2} \geq 15\right)$ para 36 graus de liberdade é superior a 0,99 . Assim, aceitase aqui uma lista de frases como estando foneticamente balanceada se o $\chi^{2}$ correspondente for inferior a 15

A obtenção de cada lista de dez frases foneticamente balanceadas é feita com auxílio de um programa de computador através das seguintes etapas:

\section{Etapa 1:}

São inicialmente escolhidas onze frases. Em seguida, é feita a transcrição fonética e, utilizando-se os símbolos correspondentes aos 37 fones, essas onze frases são armazenadas 
na memória do computador. O programa faz, então, a contagem do número de fones por frase e determina a freqüiencia com que cada um deles ocorre em cada frase.

\section{Etapa 2:}

Na Etapa 2 o programa calcula, para cada uma das onze combinações de dez frases: (a) o número total $\mathrm{N}$ de fones da lista; (b) o número de vezes que cada fone ocorreu no total de dez frases $\left(n_{i}, i=1, \ldots, 37\right)$ (c) a frequiência relativa de cada fone no total das dez frases $\left(\mathrm{f}_{\mathrm{i}}, \mathrm{i}=1, \ldots .37\right) ;(\mathrm{d}) \circ \chi^{2}$ correspondente a cada um dos fones, ou seja,

$$
\chi_{i}^{2}=\frac{\left(n_{i}-N F_{i}\right)^{2}}{N F_{i}} \quad, i=1, \ldots, 37
$$

e (e) o $\chi^{2}$ referente ao conjunto das dez frases, estabelecido da seguinte forma:

$$
\chi^{2}=\sum_{i=1}^{37} \chi_{i}^{2}
$$

\section{Etapa 3:}

Nessa etapa, o programa determina a combinação de dez frases que resulta no menor $\chi^{2}$. Se esse valor de $\chi^{2}$ for menor que 15 , será escolhida a lista de dez frases correspondente. Caso contrário, passa-se à etapa seguinte.

\section{Etapa 4:}

Com auxílio dos valores de $\chi_{\mathrm{i}}^{2}, \mathrm{f}_{\mathrm{i}}$ e $\mathrm{F}_{\mathrm{i}}, \mathrm{i}=1, \ldots, 37$, altera-se manualmente o conjunto de dez frases selecionado na Etapa 3, com o objetivo de diminuir o $\chi^{2}$ total. Com esse procedimento, obtém-se um novo conjunto de onze frases que será então reanalisado a partir da Etapa 1, e assim sucessivamente, até que seu $\chi^{2}$ seja inferior a 15.

\subsection{Listas de Dez frases Foneticamente Balanceadas}

Antes de passarmos às listas de frases, gostaríamos de chamar a atenção para os seguintes pontos:

- Em qualquer das listas foram incluidos obrigatoriamente todos os 37 fones.

- A maioria das listas contém entre 250 e 300 fones. 
- A lista que contém menor número de fones é a No 2 com um total de 176 fones.

- Pode ser de interesse avaliar a degradação por codificadores de voz sobre a qualidade do sinal original, em função de sons específicos como os fricativos, por exemplo [11]. Por esse motivo, foram incluídas na Lista $\mathrm{N}^{\circ} 3$ seis frases que concentram, em cada uma delas, sons com características semelhantes. Mais especificamente, as frases $1,2,3,4,5$ e 6 concentram, respectivamente, os seguintes tipos de som:

(1) vogais e semivogais

(2) vogais e consoantes nasais

(3) fricativas sonoras e surdas

(4) oclusivas e africadas

(5) laterais

(6) vibrantes

É importante ressaltar, finalmente, que a transcrição fonética das listas de frases tomou como referência um locutor ideal que as pronunciaria de maneira coloquial, isto é, praticando os mesmos fenômenos - elisões, reduções de ditongos, etc. - encontrados no corpus espontâneo.

\section{Lista № 1}

1. A questão foi retomada no congresso

2. Leila tem um lindo jardim

3. O analfabetismo é a vergonha do país

4. A casa foi vendida sem pressa

5. Trabalhando com união rende muito mais

6. Recebí nosso amigo para almoçar

7. A justiça é a única vencedora

8. Isso se resolverá de forma tranqüila

9. Os pesquisadores acreditam nessa teoria

10. Sei que atingiremos o objetivo

Número total de fones: 259

$$
\chi^{2}=11,847
$$




\section{Lista № 2}

1. Nosso telefone quebrou

2. Desculpe se magoei o velho

3. Queremos discutir o orçamento

4. Ela tem muita fome

5. Uma índia andava na mata

6. Zé, vá mais rápido!

7. Hoje dormirei bem

8. João deu pouco dinheiro

9. Ainda são seis horas

10. Ela saía discretamente

Número total de fones: 176

$\chi^{2}=10,433$

\section{Lista № 3}

1. Eu vi logo a Iôiô e o Léo

2. Um homem não caminha sem um fim

3. Vi Zé fazer essas viagens seis vezes

4. O atabaque do Tito é coberto com pele de gato

5. Ele lê no leito de palha

6. Paira um ar de arara rara no Rio Real

7. Foi muito difícil entender a canção

8. Depois do almoço te encontro

9. Esses são nossos times

10. Procurei Maria na copa

Número total de fones: 229

$\chi^{2}=12,123$

\section{Lista № 4}

1. A pesca é proibida nesse lago

2. Espero te achar bem quando voltar

3. Temos muito orgulho da nossa gente

4. O inspetor fez a vistoria completa

5. Ainda não se sabe o dia da maratona

6. Será muito difícil conseguir que eu venha

7. A paixão dele é a natureza

8. Você quer me dizer a data?

9. Desulpe, mas me atrasei no casamento

10. Faz um desvio em direção ao mar!

Número total de fones: 255

$\chi^{2}=12,237$

Revista da Sociedade Brasileira de Telecomunicações 


\section{Lista № 5}

1. A velha leoa ainda aceita combater

2. É hora do homem se humanizar mais

3. Ela ficou na fazenda por uma hora

4. Seu crime foi totalmente encoberto

5. A escuridão da garagem assustou a criança

6. Ontem não pude fazer minha ginástica

7. Comer quindim é sempre uma boa pedida

8. Hoje eu irei precisar de você

9. Sem ele o tempo flui num ritmo suave

10. A sujeira lançada no rio contamina os peixes

Número total de fones: 274

$\chi^{2}=11,346$

\section{Lista № 6}

1. O jogo será transmitido bem tarde

2. É possível que ele já esteja fora de perigo

3. A explicação pode ser encontrada na tese

4. Neu vôo tinha sido marcado para as cinco

5. Daqui a pouco a gente irá pousar

6. Estou certo que mereço a atenção dela

7. Era um belo enfeite todo de palha

8. O comércio daqui tem funcionado bem

9. É a minha chance de esclarecer a notícia

10. A visita transformou-se numa reunião íntima

Número total de fones: 287

$$
\chi^{2}=11,431
$$

\section{Lista № 7}

1. O cenário da história é um subúrbio do Rio

2. Eu tenho ótima razão para festejar

3. A pequena nave medirá o campo magnético

4. O prêmio será entregue sém sessão solene

5. A ação se passa numa cidade calma

6. Ela e o namorado vão a Portugal de navio

7. O adiamento surpreendeu a mim e a todos

8. A gente sempre colhe o que plantou

9. Aqui é onde existem as flores mais interessantes

10. A corrida de inverno aconteceu com vibração

Número total de fones: 299

$\chi^{2}=13,530$

34 


\section{Lista № 8}

1. Esse empreendimento será de enorme sucesso

2. As feiras livres não funcionam amanhã

3. Fumaré muito prejudicial à saúde

4. Entre com seu código e o número da conta

5. Reflita antes e discuta depois

6. As aulas dele são bastante agradáveis

7. Usar aditivos pode ser desastroso

8. O clima não é mau em Calcutá

9. A locomotiva vem sem muita carga

10. Ainda é uma boa temporada para o cinema

Número total de fones: 283

$\chi^{2}=13,457$

\section{Lista № 9}

1. Os maiores picos da Terra ficam debaixo d'água

2. A inauguração da vila é quarta-feira

3. Só vota quem tiver o título de eleitor

4. É fundamental buscar a razão da existência

5. A temperatura só é boa mais cedo

6. Em muitas regiões a população está diminuindo

7. Nunca se pode ficar em cima do muro

8. Prá quem vê de fora o panorama é desolador

9. É bom te ver colhendo flores

10. Eu me banho no lago ao amanhecer

Número total de fones: 296

$\chi^{2}=14,537$

\section{Lista No 10}

1. É fundamental chegar a uma solução comum

2. Há previsão de muito nevoeiro no Rio

3. Muitos móveis virão às cinco da tarde

4. A casa pode desabar em algumas horas

5. O candidato falou como se estivesse eleito

6. A idéia é falha, mas interessa

7. O dia está bom para passear no quintal

8. Minhas correspondências não estão em casa

9. A saída para a crise dele é o diálogo

10. Finalmente o mau tempo deixou o continente

Número total de fones: $\mathbf{2 8 9}$

$\chi^{2}=13,808$

Zevista da Sociedade Brasileira de Telecomunicaçōes

. olume 7 - Número 1 - Dezembro 1992 


\section{Lista № 11}

1. Um casal de gatos come no telhado

2. A cantora foi apresentar seu grande sucesso

3. Lá é um lugar ótimo para tomar uns chopinhos

4. O musical consumiu sete meses de ensaio

5. Nosso baile inicia após as nove

6. Apesar desses resultados, tomarei uma decisão

7. A verdade nãopoupa nem as celebridades

8. As queimadas devem diminuir este ano

9 . O vão entre o trem e a plataforma é muito grande

10. Infelizmente não comparecí ao encontro

Número total de fones: 311

\section{Lista № 12}

1. As crianças conheceram o filhote de ema

2. A bolsa de valores ficou em baixa

3. O congresso volta atrás em sua palavra

4. A médica receitou que eles mudassem de clima

5. Não é permitido fumar no interior do ônibus

6. A apresentação foi cancelada por causa do som

7. Uma garota foi presa ontem à noite

8. O prato do dia é couve com atum

9. Eu viajarei ao Canadá amanhã

10. A balsa é o meio de transporte daqui

Número total de fones: 291

$$
\chi^{2}=13,278
$$

\section{Lista № 13}

1. O grêmio ganhou a quadra de esportes

2. Hoje irei à vila sem meu filho

3. Essa magia não acontece todo dia

4. Será bom que você estude esse assunto

5. O menu incluía pratos bem saborosos

6. Podia dizer as horas, por favor?

7. A casa é ornamentada com flores do campo

8. A Terra é farta, mas não infinita

9. O sinal emitido é captado por receptores

10. A mensalidade aumentou mais que a inflação

Número total de fones: 274

$\chi^{2}=13,078$ 


\section{Lista № 14}

1. O tele-jornal termina às sete da noite

2. A cabine telefônica fica na próxima rua

3. Defender a ecologia é manter a vida

4. Nesse verão o calor está insuportável

5. Um jardim exige muito trabalho

6. O mamão que eu comprei estava ótimo

7. Meu primo falará com a gerência amanhã

8. De dia apague a luz sempre

9. A sociedade uruguaia tem que se mobilizar

10. Suas atitudes são bem calmas

Número total de fones: 273

$\chi^{2}=12,023$

\section{Lista № 15}

1. Dezenas de cabos eleitorais buscavam apoio

2. A vitória foi paga com muito sangue

3. Nossa filha tem amor por animais

4. Esse peixe é mais fatal que certas cobras

5. O time continua lutando pelo sucesso

6. Essa medida foi devidamente alterada

7. O estilete é uma arma perigosa

8. Aguarde, quinta eu venho jantar em casa

9. A mudança é lenta, porém duradoura

10. O clima não é mais seco no interior

Número total de fones: $\mathbf{2 8 3}$

$\chi^{2}=11,991$

\section{Lista № 16}

1. A sensibilidade indicará a escolha

2. A Amazônia é a reserva ecológica do globo

3. O ministério mudou demais com a eleição

4. Novos rumos se abrem para a informática

5. O capital de uma empresa depende da produção

6. Se não fosse ela. tudo teria sido contido

7. A principal personagem no filme é uma gueixa

8. Receba seu jornal em sua casa

9. A juventude tinha que revolucionar a escola

10. A atriz terá quatro meses para ensaiar seu canto

Número total de fones: $\mathbf{3 1 5}$

$$
\chi^{2}=13,466
$$

Revista da Sociedade Brasileira de Telecomunicações 


\section{Lista № 17}

1. Muito prazer em conhecê-lo

2. Eles estavam sem um bom equipamento

3. O sol ilumina a fachada de tarde

4. A correção do exame está coerente

5 . As portas são antigas

6. Sobrevoamos Natal acima das nuvens

7. Trabalhei mais do que podia

8. Hoje eu acordei muito calmo

9. Esse canal é pouco informativo

10. Parece que nascemos ontem

Número total de fones: $\mathbf{2 3 0}$

$\chi^{2}=10,741$

\section{Lista № 18}

1. Receba meus parabéns pela apresentação

2. Eu planejo uma viagem no feriado

3. Nolado de cá do rio há uma boa sombra

4. A maioria dos visitantes gosta deste monumento

5. Minha filha é especialista em música sacra

6. A casa só tem um quarto

7. A duração do simpósio é de cinco dias

8. Ao contrário de nossa expectativa, correu tranquilo

9. A intenção é obter apoio do governante

10. A fila aumentou ao longo do dia

Número total de fones: 290

$\chi^{2}=13,894$

\section{Lista № 19}

1. À noite a temperatura deve ir a zero

2. A proposta foi inspecionada pela gerência

3. O quadro mostra uma face do cotidiano

4. Já era bem tarde quando ele me abordou

5. O canário canta ao amanhecer

6. A lojinha fica bem na esquina de casa

7. Meu time se consagrou como o melhor

8. Um instituto deve servir a sua meta

9. Ele entende quando se fala pausadamente

10. Seu saldo bancário está baixo

Número total de fones: $\mathbf{2 7 7}$

$\chi^{2}=13,310$ 


\section{Lista $N^{\circ} 20$}

1. O termômetro marcava um grau

2. O discurso de abertura é bem longo

3. Eu precisei de microfone na conferência

4. Joyce esticou sua temporada até quinta

5. Nada como um almoço ao ar livre

6. Nossa filha é a primeira aluna da classe

7. Gostaria de deitar um pouco

8. Não fizemos uma viagem muito cansativa

9. Ainda tenho cinco telefonemas para dar

10. Os hoteis do sudoeste são fantásticos

Número total de fones: 278

$$
\chi^{2}=12,449
$$

\section{Agradecimentos}

Agradecemos à Helena Britto, pelo auxilio prestado na fase de digitação dos dados no computador e à Dinah Callou, por sugestões feitas a uma versão anterior deste trabalho.

\section{Referências}

[1] IEEE Recommended Practice for Speech Quality Measurements, IEEE Transacfions on Audio and Electroacoustics, vol. AU-17, No 3, Setembro 1969, pp. 225-246.

[2] P. Combescure, "20 Listes de Dix Phrases Phonétiquement Equilibrées", Revue dÁcoustique, $\mathrm{N}^{\circ} 56,1981$, pp. 34-38.

[3] CCITT ad-hoc group on $16 \mathrm{kbit} / \mathrm{s}$ speech coding (CCITT Q.21/XV), "Subjective Test Results for the $16 \mathrm{kbit} / \mathrm{s}$ LD-CELP Codec Based on the Degradation Category Rating", Doc. D19, Campinas, Junho 1990.

‘] G. Zipf, "La Psycho-Biologie du Langage", Retz, Paris, 1974.

[5] M. Delgado-Martins, "Vogais e Consoantes do Português: Estatística de Ocorrência, Duração e Intensidade", Boletim de Filologia, Vol. XXIV, Nº 1-4, 1975, pp. 1-11.

[6] D. Callou e M.H. Marques, " Os Estudos Dialetológicos no Brasil e o Projeto de Estudo da Norma Lingüística Culta”, Littera, nº 8, 1973, pp. 100-111.

[?] CNLC, Anais do Primeiro Congresso da Língua Nacional Cantada, São Paulo, Departamento de Cultura, 1938.

¿svista da Sociedade Brasileira de Telecomunicações

- slume 7 - Número 1 - Dezembro 1992 
[8] CLFT, Anais do Primeiro Congresso Brasileiro da Língua Falada no Teatro, Rio de Janeiro, Ministério da Educação e Cultura, 1958.

[9] R.V. Hogg e A.T. Craig, "Introduction to Mathematical Statistics", Macmillan Publishing Co., Inc., New York, Fourth Edition.

[10] E.L. Lehmann, "Nonparametrics: Statistical Methods Based on Ranks", MacGraw-Hill International Book Company, New York, 1975.

[11] P. Kroon e B.S. Atal, "Strategies for Improving the Performance of CELP Coders at Low Bit Rates", Proceedings of the IEEE International Conference on Acoustics, Speech, and Signal Processing, New York, U.S.A., April 1988, pp. 151-154.

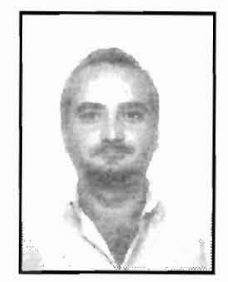

Abraham Alcaim formou-se em Engenharia Elétrica pela PUC/Rio em 1975, obteve o título de Mestre em Ciências em Engenharia Elétrica pela mesma Universidade em 1977, e os títulos de D.I.C. e PhD em Engenharia Elétrica pelo Imperial College of Science and Technology, University of London, em 1981. Tem mais de 15 anos de experiência nas áreas de codificação digital e transmissão de formas de onda e processamento digital de sinais de voz, tendo atuado nos últimos dois anos também na área de processamento de imagens. É autor de 30 artigos nessas áreas, publicados em revistas e conferências nacionais e internacionais. Em 1984 desempenhou atividades na área de processamento de voz, como Pesquisador Visitante no Centre National d'Etudes de Télécommunications (CNET), em Lannion, França. É Professor Associado do Centro de Estudos em Telecomunicações da PUC/Rio, onde atua, desde 1976, no grupo de Sistemas de Telecomunicações. Foi presidente da Comissão de Programa do SBT/IEEE International Telecommunications Symposium (ITS'90) realizado no Rio de Janeiro em setembro de 1990 e é o presidente da Comissão de Programa do ITS'94, a ser realizado também no Rio de Janeiro em agosto de 1994. Desde dezembro de 1991 se encontra em licença sabática da PUC/Rio, como Pesquisador Assessor do Centro Científico Rio da IBM Brasil, onde vem desenvolvendo trabalhos na área de codificação digital de imagens. 


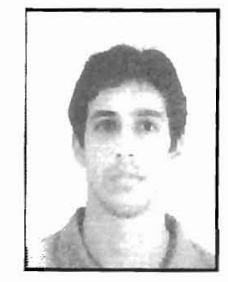

José Alberto Solewicz é aluno do curso de pós-graduação em Sistemas de Comunicações da PUC/Rio, desenvolvendo tese em síntese de roz a partir de texto. É graduado em Engenharia Elétrica pelo TECHNIONIsrael Institute of Technology (1990) onde projetou, com apoio da Intel, uma placa independente para reconhecimento de voz. Como bolsista de Aperfeiçoamento Científico pelo CNPq (1991), atuou no projeto "Análises Acústicas do Português falado no Rio de Janeiro", desenvolvido no Laboratório de Fonética Acústica da Faculdade de Letras da UFRJ, e da simulação de sistemas para reconhecimento de palavras, da COPPE-UFRJ. Suas áreas de interesse são síntese e reconhecimento de voz.

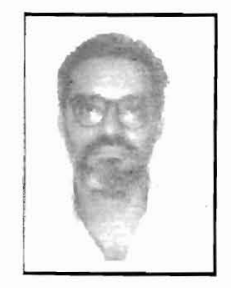

João Antônio de Moraes é Professor Visitante do Departamento de Letras Vernáculas da Faculdade de Letras da UFRJ, sendo responsável pela instalação do Laboratório de Fonética Acústica e pela orientação dos trabalhos nele desenvolvidos. Formado em Letras pela Universidade do Estado da Guanabara (1975) e em Medicina pela Universidade Federal do Rio de Janeiro (1976), tem Mestrado em Ciências da Linguagem (1979) pela Universidade de Paris III e Doutorado em Fonética Instrumental e Funcional (1984) pela mesma Universidade, com uma tese sobre a entoação do português falado no Rio de Janeiro. Sua principal área de interesse é a descrição prosódica do português (ritmo, acento, entoação), sendo autor de diversos trabalhos sobre o tema em publicações especializadas no país e no exterior. Seus outros interesses são a descrição acústica do português do Brasil e a síntese da voz. Prepara, no momento, um manual sobre a prosódia do Português do Brasil. Pesquisador II A do CNPq, integra o grupo que vem elaborando a Gramática do Português Falado. 